\title{
DYNAMISATION OF TIBIAL FRACTURES
}

\author{
J. B. RICHARDSON, T. N. GARDNER, J. R. W. HARDY, M. EVANS, J.-H. KUIPER, J. KENWRIGHT
}

From Glenfield General Hospital and Leicester Royal Infirmary, England

We studied the effect of 'dynamisation' on tibial fractures in six patients treated by the Dynamic Axial Fixator. In the early stages, peak cyclic movement at two to four weeks averaged $0.75 \mathrm{~mm}(0.19$ to 1.02$)$ on the medial side of the bone and $0.86 \mathrm{~mm}(0.21$ to 1.25$)$ on the lateral side. The amount of movement correlated with the applied load and the fracture stiffness. After unlocking the fixator column at six weeks, progressive closure of the gap averaged $1.3 \mathrm{~mm}(0.1$ to 3.5$)$.

Cyclic movement is produced by early weight-bearing with the fixator column locked. Progressive closure occurs after unlocking the column, and is often associated with a reduction in cyclic movements. The effects of dynamisation on movement at the fracture site should be defined separately, in terms of cyclic movement and of progressive closure.

J Bone Joint Surg [Br] 1995;77-B:412-6.

Received 23 May 1994: Accepted 22 August 1994

J. B. Richardson, MD. FRCS, Professor of Orthopaedics

J.-H. Kuiper, MSc, PhD, Biomechanical Engineer

The Robert Jones and Agnes Hunt Orthopaedic Hospital, Oswestry. Shropshire SY10 7AG, UK.

J. R. W. Hardy, FRCS, Lecturer in Orthopaedics

Glenfield General Hospital. Groby Road, Leicester LE3 9QP, UK.

T. N. Gardner, BSc, DPhil, Senior Research Scientist

M. Evans. Biomechanical Engineer

J. Kenwright, MA, MD, FRCS. Professor of Orthopaedics

Nuffield Orthopaedic Centre NHS Trust. University of Oxford. Windmill

Road, Headington, Oxford OX3 7LD. UK.

Correspondence should be sent to Mr J. R. W. Hardy.

(1)1995 British Editorial Society of Bone and Joint Surgery $0301-620 X / 95 / 3961 \$ 2.00$
Some movement at a fracture site is believed to induce healing by callus formation (Lindholm et al 1970). External fixators can be modified to control the amount of movement and force (De Bastiani, Aldegheri and Brivio 1984; Kenwright et al 1991) and it is important to determine the best pattern of movement for healing at different stages of callus formation and maturation.

We have shown that, using the Dynabrace fixator (Richards, Cambridge, UK), the application of cyclic movements within two weeks from injury gave a $20 \%$ improvement in healing rates (Kenwright et al 1991). For the Dynamic Axial Fixator (Orthofix SRL, Verona, Italy), unlocking is recommended at four to six weeks and gave an average healing time of 15.5 weeks for closed tibial fractures (De Bastiani et al 1984). The ability of these frames to allow axial movement has been questioned. In the Dynabrace early cyclic movements at the fracture site were small, of the order of $0.2 \mathrm{~mm}$ at two weeks (Kershaw, Cunningham and Kenwright 1993). Variable cyclic movements have been measured on the frame of the Orthofix fixator after unlocking at four to six weeks (Pohl and Williams 1989; Ralston et al 1990).

There have been few reports of the normal pattern of movement in externally fixated fractures, or the true effect of unlocking the fixator column. The development of new techniques to measure displacement at the fracture site (Evans et al 1994; Gardner et al 1994) now allows accurate determination of these movements.

\section{PATIENTS AND METHODS}

We studied six consecutive patients with tibial diaphyseal fractures treated by an Orthofix Dynamic Axial Fixator by measuring movement at the fracture gap. They were all men and their ages ranged from 22 to 57 years (Table I). The fixator had been applied with six $130 \mathrm{~mm}$ bone screws inserted into the anteromedial aspect of the tibia. Six weeks after fracture, the fixator column was unlocked. Fracture stiffness was measured at each two-weekly visit. Frames were removed when fracture stiffness had reached $15 \mathrm{Nm} /$ degree (Richardson et al 1994) and no further splint was applied.

We measured movement in two ways. During walking, with simultaneous recording of weight-bearing, the relative movement at the fracture site was measured using the Oxford Micromovement Transducer (OMT; Gardner et al 
Table I. Details of the six patients studied. They were all male

\begin{tabular}{|c|c|c|c|c|c|}
\hline Case & $\begin{array}{l}\text { Age } \\
\text { (yr) }\end{array}$ & $\begin{array}{l}\text { AO class } \\
\text { of fracture* }\end{array}$ & $\begin{array}{l}\text { Type of } \\
\text { wound }+\end{array}$ & $\begin{array}{l}\text { Peak cyclic } \\
\text { movement } \\
(\mathrm{mm})\end{array}$ & $\begin{array}{l}\text { Healing } \\
\text { time } \\
\text { (wk) }\end{array}$ \\
\hline 1 & 22 & 42B2.2 & 2 & 0.92 & 26 \\
\hline 2 & 23 & 42B 3.3 & 0 & 1.03 & 16 \\
\hline 3 & 33 & $42 \mathrm{~B} 2.3$ & 1 & 1.04 & 10.8 \\
\hline 4 & 57 & 42B I.2 & 0 & 1.13 & 13 \\
\hline 5 & 28 & $42 \mathrm{~A} .3 .3$ & 0 & 0.85 & 17 \\
\hline 6 & 2.3 & $42 \mathrm{~A} 2.3$ & 0 & 1.25 & 24.1 \\
\hline
\end{tabular}

1994). The OMT is fixed to the fixator pins and transforms relative movement between the sets of pins into three translational and three rotational components of motion at the centre of the fracture, with an accuracy of $0.025 \mathrm{~mm}$ and $0.025^{\circ}$ in all three planes and axes. In each gait cycle these movements were fully recoverable and henceforth are termed cyclic.

From each set of measurements, we determined the maximum axial component of the relative motion at the centre of the fracture. From the bone geometry as measured on radiographs, we transformed the relative movements at the fracture centre into length changes between the opposing edges of the bone fragments, taking into account the effects of both axial and bending movements (Fig. 1), and providing a measure of the change in length of the soft tissues on either side of the fracture.

Relative migration or closure of the fracture gap was measured from radiographs using a Vernier calliper gauge. Measurements were made by one observer at three points in each plane and an average taken of the results. The standard deviation of these measurements was $0.2 \mathrm{~mm}$. This movement was non-recoverable and was therefore termed progressive.

\section{RESULTS}

The maximum cyclic axial, medial and lateral movements and the maximum ground reaction forces are represented in Figure 2. The maximum ground reaction force is seen to rise at different rates.

Cyclic movements. Recoverable movement was seen in all patients at two weeks after injury with a mean of $0.74 \mathrm{~mm}$ ( 0.20 to 0.98$)$. The amount of movement correlated with the applied load (Fig. 3), reducing as the fracture stiffness increased.

The effect of unlocking the fixator column at six weeks varied. Five patients (cases 2 to 6 ) showed relatively large cyclic movements of up to $1 \mathrm{~mm}$ in the early period, with smaller movements of about $0.3 \mathrm{~mm}$ during later periods (Figs $2 \mathrm{~b}$ to $2 \mathrm{f}$ ). In these five patients, unlocking the fixator was associated with an immediate moderate reduction in cyclic movement. The reduction of movement was greater after another two weeks, despite increased loading of the fracture.

\section{Left leg}

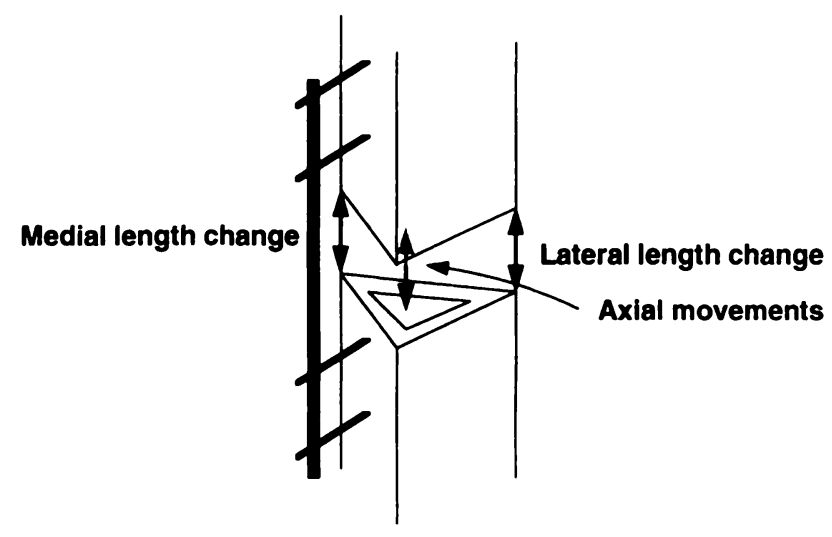

Fig. 1

Diagram showing the position of the fixator and of medial, axial and lateral movements relative to the fracture gap.

The sixth patient (case 1) showed small movements of $0.2 \mathrm{~mm}$ during the early stage. larger movements $(0.7 \mathrm{~mm})$ during the intermediate stage and small movements $(0.2 \mathrm{~mm})$ during the late stage of healing (Fig. 2a). Unlocking the fixator increased the cyclic movement, and this decreased only later when fracture stiffness was rising.

Before the fixator was unlocked, the average movement on the lateral side of the bone (away from the fixator) was $12 \%$ greater than that on the medial side. Unlocking changed this ratio: average movements on the medial side became $2 \%$ larger than those on the lateral side.

Progressive movements. Unrecoverable movement was seen in all patients after unlocking the fixator, with a mean of $1.3 \mathrm{~mm}$ ( 0.1 to 3.5 ; Table II). Transverse fractures did not migrate as far as the oblique or comminuted fractures.

All patients showed steady progress in fracture healing, although the rate of healing revealed by stiffness measurements varied widely (Fig. 4). The average time to independent weight-bearing for the whole group was 17.8 weeks.

\section{DISCUSSION}

Our previous studies have indicated that cyclic movements applied by a pump soon after fracture correlate with faster healing rates as shown by measurements of fracture stiffness (Goodship and Kenwright 1985; Kenwright et al 1991). We have now shown that cyclic movements do occur during walking on an Orthofix unilateral fixator with a locked column, giving axial movements with a mean amplitude of $0.74 \mathrm{~mm}$, usually in proportion to the load applied at that time (Fig. 3). This is a larger average amount of early cyclic movement than the $0.2 \mathrm{~mm}$ reported for the Dynabrace fixator (Kershaw et al 1993).

We found a wide variation in the amount of cyclic 


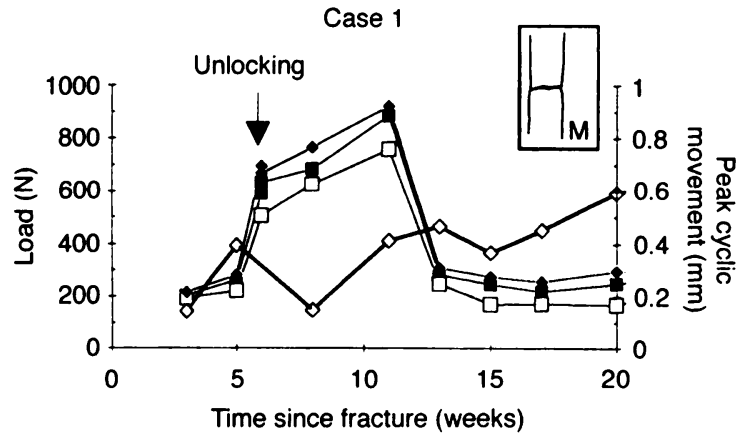

Fig. 2a

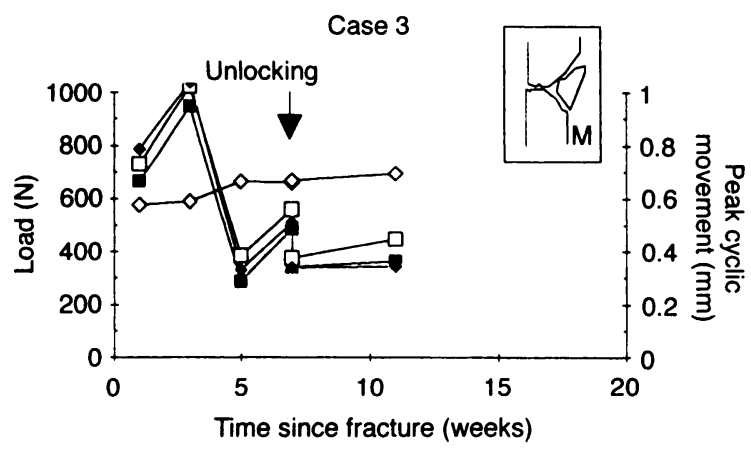

Fig. 2c

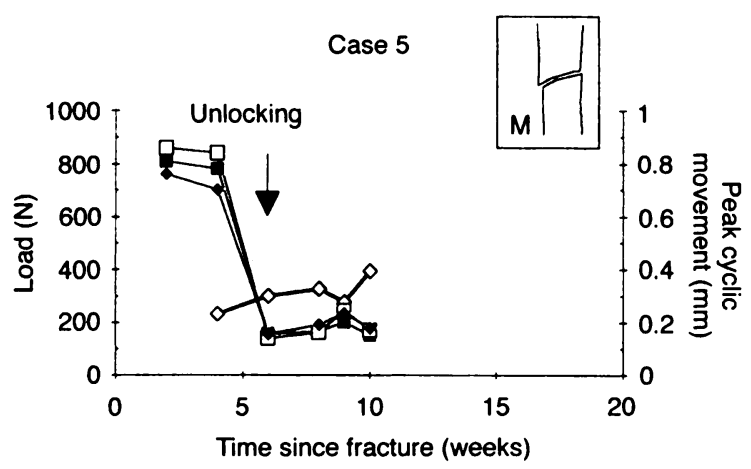

Fig. 2e

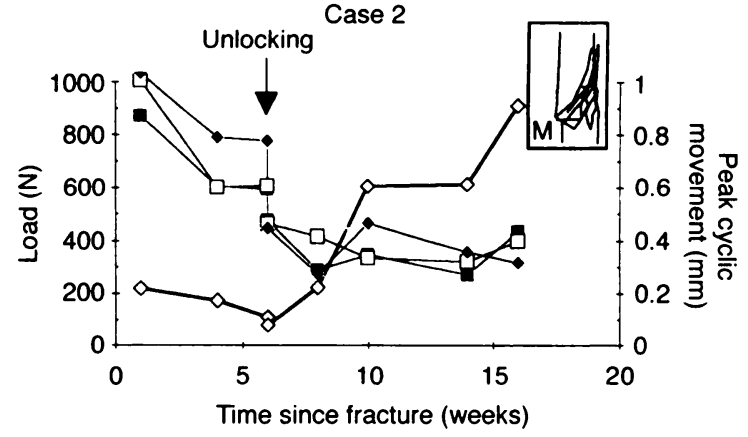

Fig. $2 b$

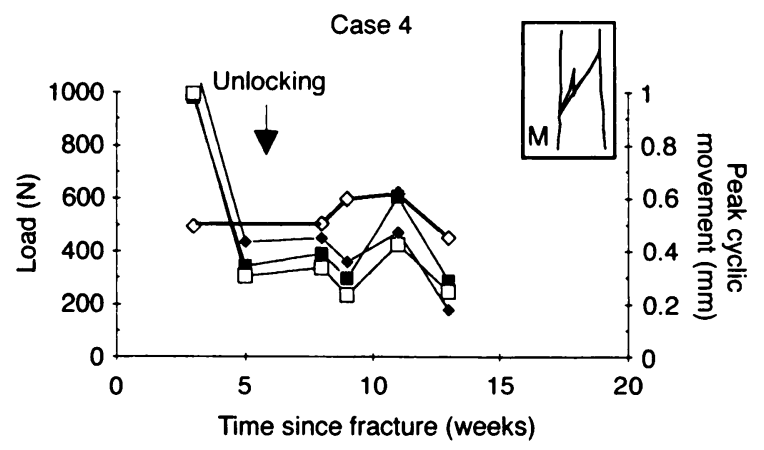

Fig. 2d

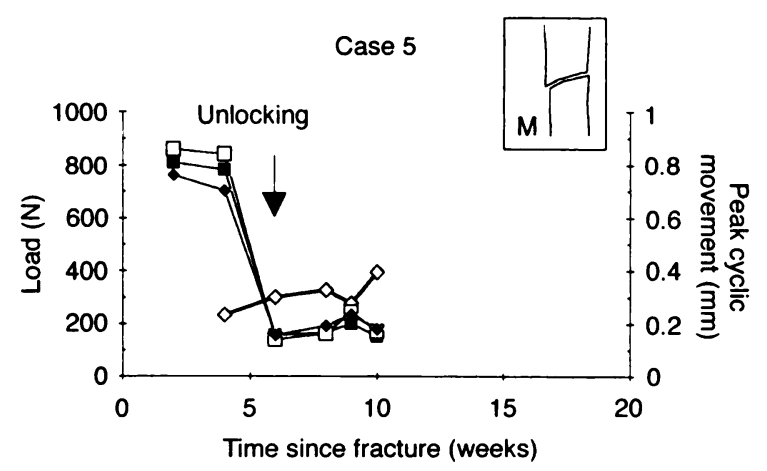

Fig. $2 f$

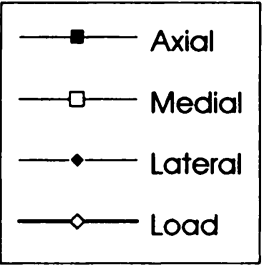

Charts showing cyclic movements and weight-bearing forces for each patient. The diagrams of the fracture pattern are marked $\mathrm{M}$ on the medial side. 


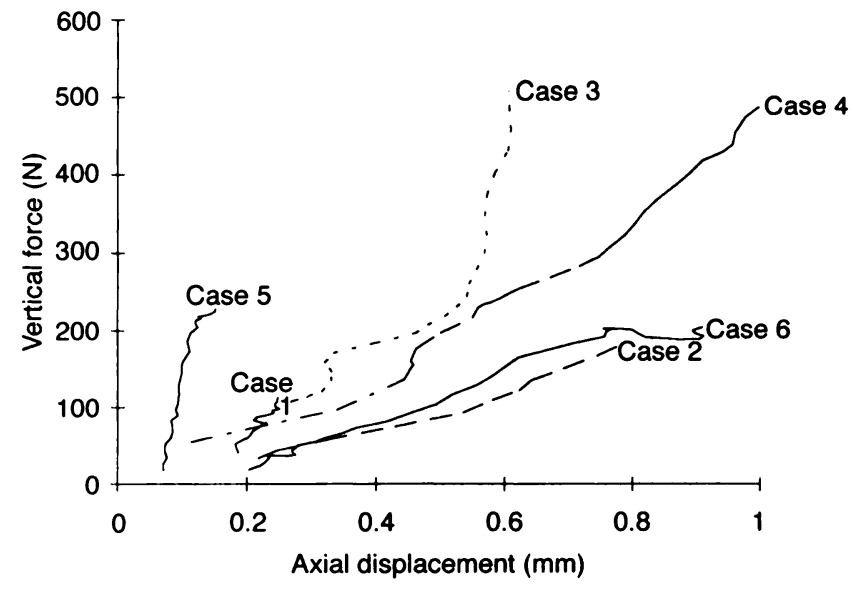

Fig. 3

Load versus movement at two to four weeks for each case during walking with weight-bearing.

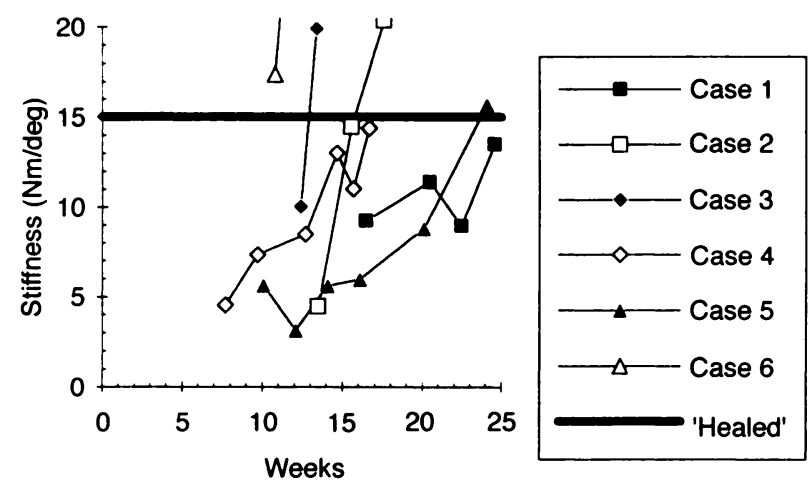

Fig. 4

Pattern of rising fracture stiffness for each case.

movement $(0.20$ to $0.98 \mathrm{~mm})$, largely due to the variations in fracture geometry, tissue properties and loads applied by the patients. In the only patient showing small early movements (Fig. 2a), there was no visible fracture gap at the lateral cortex.

The cyclical subperiosteal movement at the lateral cortex was $12 \%$ larger than that at the medial cortex, as a result of bending in the plane of the bone screws. This finding may explain the common observation of greater amounts of lateral callus in patients treated in unilateral external fixation.

Unlocking the fixator was generally associated with a reduction in cyclic movement, either immediately or within two weeks. The reduction in cyclic movements in the later weeks of healing may be explained by rising fracture stiffness but does not explain the immediate fall at the time of unlocking (Fig. 4). In only one patient did unlocking at six weeks increase the cyclic movement (case 1, Fig. 2a), and we consider this to be due to compressive prestressing of the fracture site at the time of reduction and fixation.
Table II. Fracture gap measurements before and after unlocking the fixator column, and the amount of progressive closure after unlocking

\begin{tabular}{llll}
\hline & $\begin{array}{l}\text { Fracture gap } \\
\text { Before } \\
\text { unlocking }\end{array}$ & $\begin{array}{l}\text { After } \\
\text { unlocking } \\
(\mathbf{m m})\end{array}$ & $\begin{array}{l}\text { Progressive } \\
\text { movement } \\
(\mathbf{m m})\end{array}$ \\
\hline 1 & 0.4 & 0.0 & 0.4 \\
2 & 3.8 & 0.8 & 3.0 \\
3 & 1.2 & 1.0 & 0.2 \\
4 & 1.9 & 1.1 & 0.8 \\
5 & 1.5 & 1.4 & 0.1 \\
6 & 3.7 & 0.2 & 3.5 \\
\hline
\end{tabular}

In all five unstable fractures, unlocking the fixator was associated with progressive movement averaging $1.3 \mathrm{~mm}$ with closure of the fracture gap (Table II). This amount of movement is similar to that reported for measurements made on the body of the fixator by Kay, Ross and Powell (1989): $50 \%$ of patients showed shortening of $1 \mathrm{~mm}$. The actual displacement may be larger than that measured radiographically, because of bone resorption at the bone ends, but since we record only relative movements, this method of measurement is probably satisfactory.

The inverse relationship which we found between cyclic movement and progressive closure in this study is predictable on mechanical grounds. The locked fixator and bone screws act as a spring, and reopen the fracture gap after it has been closed by the application of load by weightbearing. Unlocking the fixator allows the gap to close permanently and stops the spring-like action. Permanent closure of any gap probably allows more direct loadtransfer through the fracture, thus reducing the share of axial load taken by the fixator. This must reduce the load on the bone screws, and may explain the low incidence of screw problems reported by De Bastiani et al (1984).

The term 'dynamisation' has become associated with both cyclic movements (Paley et al 1990; Calhoun et al 1992) and with progressive, non-recoverable displacement (Melendez and Colon 1989; Egger et al 1993), and this has caused some to expect increased cyclic movement after 'dynamisation' by unlocking, while others expect progressive movement or gap closure. This may explain the concern of Pohl and Williams (1989) when they sometimes failed to obtain cyclic movement after unlocking a fixator: they expected dynamisation to increase movement. We suggest that movement at a fracture site should always be defined as either cyclic or progressive.

The unpredictability of healing times for individual tibial fractures may be explained partly by the wide variation in both cyclic movement and progressive closure in our small series. The patients with early cyclic movements of more than $0.5 \mathrm{~mm}$ usually healed faster, as measured objectively by fracture stiffness (Fig. 4). One patient (case 6), however, with large early cyclic movements of $1.25 \mathrm{~mm}$ and later a progressive movement of $3.5 \mathrm{~mm}$ had slow healing. In this case the initial fracture gap of $3.7 \mathrm{~mm}$ probably contributed 
to the delay. Relatively large cyclic movements may well act as a stimulus to the growth of callus in the early weeks, while increased stability and compression of callus may be more appropriate stimuli in the later phase of callus maturation. Much larger studies will be required to define the optimum size, frequency, and direction of movements which are likely to influence fracture healing.

We have shown that early cyclic movement will be obtained in some fractures by allowing weight-bearing with the fixator column locked. Unlocking the column at four to six weeks usually allows progressive movement which may also be beneficial, but may also cause a reduction in cyclic movements. For research purposes it is important to consider the effect of 'dynamisation' in terms of both cyclic movement and progressive closure at the fracture site.

The authors would like to thank our patients for their co-operation in this study, and the Wishbone Trust for financial support.

Although none of the authors have received or will receive benefits for personal or professional use from a commercial party related directly or indirectly to the subject of this article, benefits have been or will be received but are directed solely to a research fund, foundation, educational institution, or other non-profit institution with which one or more of the authors is associated.

\section{REFERENCES}

Calhoun JH, Li F, Ledbetter BR, Gill CA. Biomechanics of the Ilizarov fixator for fracture fixation. Clin Orthop 1992;280:15-22.

De Bastiani G, Aldegheri R, Brivio LR. The treatment of fractures with a dynamic axial fixator. J Bone Joint Surg [Br] 1984;66-B:538-45.

Egger EL, Gottsauner-Wolf F, Palmer J, Aro HT, Chao EY. Effects of axial dynamization on bone healing. J Trauma 1993:34:185-92.

Evans M, Gardner TN, Hardy JRW, Richardson JB, Ten Voorde WB. The effect of 'dynamisation' on fracture site movement with the orthofix D.A.F. fixator. J Bone Joint Surg [Br] 1994;76-B Supp II \& III:88.
Gardner TN, Evans M, Simpson AHRW, Turner-Smith AR. Threedimensional movement at externally fixated tibial fractures and osteotomies during normal patient function. Clin Biomech 1994:9:51-9.

Goodship AE, Kenwright J. The influence of induced micromovement upon the healing of experimental tibial fractures. J Bome Joint Surg [Br] 1985:67-B:650-5.

Gustilo RB, Anderson JT. Prevention of infection in the treatment of one thousand and twenty-five open fractures of long bones: retrospective and prospective analysis. J Bome Joint Surg /Am/ 1976;58-A:453-8.

Kay PR, Ross ERS, Powell ES. Development and clinical application of an external fixator monitoring system. J Biomed Eng 1989:11:240-4.

Kenwright J, Richardson JB, Cunningham JL, et al. Axial movement and tibial fractures: a controlled randomised trial of treatment. $J$ Bome Joint Surg [Br] 1991:73-B:654-9.

Kershaw CJ, Cunningham JL, Kenwright J. Tibial external fixation. weight bearing and fracture movement. Clin Orthop 1993:293:28-36.

Lindholm RV, Lindholm TS, Toikkanen S, Leino R. Effect of forced inter-fragmental movements on the healing of tibial fractures in rats. Acta Orthop Scand 1970:40:721-8.

Melendez EM, Colon C. Treatment of open tibial fractures with the Orthofix fixator. Clin Orthop 1989:241:224-30.

Müller ME, Nazarian S, Koch P, Schatzker J. The comprehensive classification of fractures of long bones. Berlin. etc: Springer-Verlag. 1990.

Paley D, Fleming B, Catagni M, Kristiansen T, Pope M. Mechanical evaluation of external fixators used in limb lengthening. Clin Orthop 1990;250:50-7.

Pohl AP, Williams DR. The dynamic axial loading properties of the Orthofix fixator. Proc 13th Int Conf Minnesota, etc: 1989:63.

Ralston JL, Brown TD, Nepola JV, Williams DR, Marsh JL. Mechanical analysis of the factors affecting dynamization of the Orthofix Dynamic Axial Fixator. J Orthop Trauma 1990:4:449-57.

Richardson JB, Cunningham JL, Goodship AE, O'Connor BT, Kenwright J. Measuring stiffness can define healing of tibial fractures. $J$ Bone Joint Surg [Br] 1994;76-B:389-94 